\title{
The Direct Enhancement of Positive Palatability by Chlordiazepoxide is Antagonized by Ro 15-1788 and CGS 8216
}

\author{
DALLAS TREIT \\ Department of Psychology, Dalhousie University, Halifax, Nova Scotia, B3H 4JI \\ KENT C. BERRIDGE AND CHARLES E. SCHULTZ \\ Department of Psychology, University of Michigan, Ann Arbor, MI 48104-1687
}

\author{
Received 1 December 1986
}

\begin{abstract}
TREIT, D., K. C. BERRIDGE AND C. E. SCHULTZ. The direct enhancement of positive palatability by chlordiazepoxide is antagonized by Ro 15-1788 and CGS 8216. PHARMACOL BIOCHEM BEHAV 26(4) 709-714, 1987.-In a previous study, it was found that positive, palatability-dependent consummatory reactions in rats to intraorally infused tastes were facilitated by chlordiazepoxide $(10 \mathrm{mg} / \mathrm{kg})$. In contrast, the rats' more neutral or aversive reactions to these tastes were not facilitated by chlordiazepoxide. This suggested that chlordiazepoxide might selectively enhance the positive palatability of tastes. This effect was replicated in the present experiment, and in addition, the benzodiazepine antagonists Ro 15-1788 and CGS 8216 were found to counteract the enhancement of positive ingestive reactions produced by chlordiazepoxide. These antagonist effects generally suggest that the benzodiazepine receptor complex may be involved in making tastes more palatable after chlordiazepoxide administration.
\end{abstract}

Palatability Chlordiazepoxide Ro 15-1788 CGS 8216

IT is well known that anxiolytics such as the benzodiazepines and barbiturates tend to increase food or fluid intake in a wide variety of species, including mice, rats, hamsters, pigeons, cats, dogs, sheep, horses, monkeys, and humans $[1-4,10,13,15,17,20,21,24,26,27,32,35,37,39]$. Nevertheless, the general mechanisms that might mediate intake facilitation by anxiolytics remain controversial (see [19] for a recent review).

Although there are a number of plausible interpretations of this facilitative effect [19], two contrasting views are dominant. The first view is that facilitation is due to a direct, drug-induced increase in the motivation to consume foods and/or fluids (e.g., increased "appetite"; [18]). The second is that facilitation is an indirect consequence of an "antianxiety" drug effect: Anxiolytics reduce "fearful" or "aversive" aspects of the test situation (e.g., novelty, painful stimulation), which otherwise suppress consumption (e.g., $[12,36]$.

Until recently, intake measures have been the primary source of support for each of these contrasting views (e.g., $[23,36])$. However, simple intake measures cannot discriminate between the appetite-enhancing effects of drugs, the anti-anxiety effects, or the combination of these effects. Thus, a resolution to this ambiguity seems to depend on a measure of consummatory motivation that is independent of fear motivation.

Recently, Berridge and Treit [8] suggested that an intraoral, taste-infusion paradigm $[28,29]$ provides a useful way to determine whether or not anxiolytics directly facilitate consummatory motivation (e.g., increase appetite). In this paradigm, solutions of different taste (e.g., sucrose, salt, quinine) are infused into the rat's mouth through intraoral cannulae. The rat's species-typical response to these infused tastes (e.g., lateral tongue protrusions, face-washing, forelimb flailing) correspond quite closely with normal intake of solutions of these tastes [9], as well as with humans" ratings of the hedonic values of these tastes $[6,14]$. But the most important advantage of the taste-infusion paradigm is that it is particularly sensitive to variables that directly affect palatability, in contrast to the more diffuse variables that can indirectly affect food intake, such as anxiety or fear $[8,33]$.

Using this paradigm, Berridge and Treit found that the prototypical anxiolytic, chlordiazepoxide (CDP), significantly increased "positive" taste reactions (i.e., "ingestive actions"), while having little or no effect on "neutral" or "aversive" taste reactions. This facilitation of ingestive reactions occurred with every taste tested. These results strongly suggested that anxiolytics such as CDP enhance the 
positive palatability of tastes, and in this way increase the hedonic or reinforcing value of foods or tluids.

In addition to providing a fairly strong argument against the use of paradigms that involve food or fluid reinforcement to test "anxiolytic" drug effects (e.g., the Geller "conflict" test). the results of the Berridge and Treit study suggest that the "GABA/benzodiazepine-receptor-complex" $[30,34]$, where CDP acts as an agonist, might be importantly involved in the modulation of food and fluid reinforcement, (cf. [19]). Stronger evidence of this relationship would be provided, however, by demonstrating that benzodiazepine antagonists, such as Ro 15-1788 [30] or CGS 8216 [11] could inhibit the selective facilitation of ingestive reactions produced by CDP. Thus, the purpose of this experiment was to investigate the effects of Ro 15-1788 and CGS 8216 on the facilitation of rats' positive ingestive actions induced by CDP.

\section{METHOD}

\section{Animals}

Twelve, naive, male Sprague-Dawley rats (250-350 g). purchased from Charles River Laboratories were housed in groups of two throughout all phases of the experiment. under a 12/12 hr light cycle (lights on 7:00 a.m.). Purina rat chow and water were available ad lib.

\section{Cannulae Implantation}

Animals were surgically implanted with bilateral. intraoral cannulae, under ketamine $(100 \mathrm{mg} / \mathrm{kg})$ and acepromazine $(1 \mathrm{mg} / \mathrm{kg})$ anaesthesia, according to procedures described by Grill and Norgren [29]. The cannulae enter the head dorsally, where they are anchored to the skull with stainless steel screws and acrylic cement. They then enter the mouth just lateral to the first maxillary molar. Fine tubing (PE 10) can be fitted inside the cannulae, which allows the infusion of the taste solutions [29].

\section{Taste Stimuli and Drug Administration}

The taste stimuli used in the present study were the same as those used in the Berridge and Treit study: $0.03 \mathrm{M}$ sucrose, which primarily elicits ingestive actions: $0.01 \mathrm{M} \mathrm{HCl}$. which elicits ingestive and aversive reactions; and $3 \times 10^{-5.3} \mathrm{M}$ quinine $\mathrm{HCl}$, which typically elicits aversive reactions. These particular concentrations were chosen in order to avoid possible ceiling effects. which might tend to obscure any facilitative effect of CDP (cf. [8]).

The experiment included two phases. In Phase I, the 12 rats were injected with CDP. saline. Ro 15-1788, and the combination of Ro 15-1788 and CDP, in a randomized order. In Phase II, seven of these rats still had operational cannulae, and subsequently were subjected to the same drug regimen, except that CGS 8216 was injected instead of Ro 15-1788. During each phase, each taste stimulus was presented four times. on consecutive days: once after the rat had received an intraperitoneal (IP) injection of $10 \mathrm{mg} / \mathrm{kg}$ of CDP: once after an IP injection of an equal volume $(1 \mathrm{ml} / \mathrm{kg})$ of isotonic saline; once after an IP injection of $10 \mathrm{mg} / \mathrm{kg}$ of the antagonist Ro 15-1788 (Phase I) or $10 \mathrm{mg} / \mathrm{kg}$ CGS 8216 (Phase II); and once after an IP injection of the combination of $10 \mathrm{mg} / \mathrm{kg} \mathrm{CDP}$ and $10 \mathrm{mg} / \mathrm{kg}$ Ro $15-1788$ (Phase I) or 10 $\mathrm{mg} / \mathrm{kg}$ of CDP and $10 \mathrm{mg} / \mathrm{kg}$ of CGS 8216 (Phase II). The antagonists were suspended in saline by untrasonification and immediately injected in a volume of $1 \mathrm{ml} / \mathrm{kg}$, whereas CDP was simply dissolved in saline and injected in a volume of $1 \mathrm{ml} / \mathrm{kg}$. Agonists and antagonists were injected $30 \mathrm{~min}$ before the taste test.

Previous studies have shown $10 \mathrm{mg} / \mathrm{kg}$ CDP to be within the range that reliably promotes consummatory-related behavior in rats $[15,17,18,20,21,23]$. The doses of Ro 15-1788 and CGS 8216 chosen in the present study are clearly within the range where the facilitative effects of benzodiazepines on consumption can be reliably inhibited [19], in many cases without "intrinsic" inhibitory effects on consumption [16. $19,22]$. However, recent studies indicate that CGS 8216 can have intrinsic (i.e.. "inverse agonist") effects on consummatory behavior. For example. CGS 8216 by itself can inhibit consummatory behavior in rats [5], especially when the ingested substances are highly palatable [25.31]. Thus, although the primary question of this study is simply whether benzodiazepine antagonists will inhibit the effects of CDP on rats positive reactions to infused tastes, a related question is whether antagonistic effects, especially those of CGS 8216 , will be accompanied by inverse agonist effects, previously demonstrated in simple intake paradigms (e.g., [31]).

Before the first test phase, each rat received three injections of $10 \mathrm{mg} / \mathrm{kg}$ CDP over three consecutive days in order to minimize any initial sedative effects of the drug (cf. [8]). In addition. during the two days immediately preceding the experiment. the rats were individually placed into the round. Plexiglas test chamber. with cannulae connected to a taste solution delivery tube. then allowed a $5 \mathrm{~min}$ habituation to the chamber, after which a $1 \mathrm{ml}$ volume of distilled water was infused into the rats ${ }^{\circ}$ mouth, at a constant rate over 1 min (i.e., the same procedure used for subsequent presentation of taste stimuli).

\section{Behavioral Measures and Statistical Analysis}

During the $10 \mathrm{~min}$ of each test, each rat was scored for the occurrence of ingestive, neutral. and aversive actions (ct. [8]). Brietly, these actions were scored as (1) ingestive (i.e.. paw licking: lateral tongue protrusions: and midline tongue protrusions), (2) neutral (rhythmic mouth movement without tongue protrusion: passive drip of the fluid from the mouth), (3) aversive (gapes: large openings of the mandible with retraction of the lower lips: chin rubbing: bringing the mouth in contact with the floor and projecting the body forward; face washing: forelimb flails: shaking of the forelimb with a frequency greater than $60 \mathrm{~Hz}$; headshaking: at a frequency greater than $60 \mathrm{~Hz}$ : paw treading: planting of the forelimbs on the tloor and alternating strokes forward and back: and rapid locomotor movement about the chamber (see [28.29] for further information on the classification of these actions).

Videotapes of these behaviors were scored at $1 / 10$ speed by an observer blind to the drug condition of the rats. Instances of ingestive, neutral. and aversive reactions under each of the taste and drug conditions were scored for each animal. For the purpose of quantifying the number of responses emitted. discrete actions such as lateral tongue protrusions, gapes, chin rubs, bouts of face washing, forelimb tlailing. headshakes, paw treading. and locomotion were recorded each time they occurred. Continuous actions that typically persist for relatively long periods were recorded as follows: paw licks. mouth movements. and passive dripping were recorded in $5-\mathrm{sec}$ bins (any uccurrence of these behaviors up to 5 sec duration was counted as a single occurrence). Rhythmic tongue protrusions were scored in the same way in $2-\sec$ bins. The sum of behaviors in each 
TABLE 1

ANALYSIS OF THE RESULTS OF PHASE I

\begin{tabular}{lccccl}
\hline Taste & Reaction & $d f$ & $\mathrm{~F}$ & $p$ & New'man-Keuls $r<0.05$ \\
\hline 0.03 M Sucrose & Ingestive & 3.33 & 9.53 & $<0.001$ & $\mathrm{CP}>\mathrm{SA}: \mathrm{RO}+\mathrm{CP}<\mathrm{CP}:$ \\
& & & & & $\mathrm{RO}>\mathrm{SA}$ \\
& Neutral & 3.33 & 2.66 & $>0.06$ & nil \\
$0.01 \mathrm{M} \mathrm{HCl}$ & Aversive & 3.33 & 1.65 & $>0.19$ & nil \\
& Ingestive & 3.33 & 7.97 & $<0.001$ & $\mathrm{CP}>\mathrm{SA} ; \mathrm{RO}+\mathrm{CP}>\mathrm{SA}$ \\
& Neutral & 3.33 & 0.77 & $>0.5$ & nil \\
$3 \times 10^{-5} \mathrm{M} \mathrm{QHCl}$ & Aversive & 3.33 & 1.88 & $>0.1$ & nil \\
& Ingestive & 3.33 & 16.57 & $<0.001$ & $\mathrm{CP}>\mathrm{SA}: \mathrm{RO}+\mathrm{CP}<\mathrm{CP}$ \\
& Neutral & 3.33 & 11.38 & $<0.001$ & $\mathrm{CP}<\mathrm{SA}: \mathrm{RO}+\mathrm{CP}>\mathrm{CP}$ \\
& Aversive & 3.33 & 1.69 & $>0.18$ & nil \\
\hline
\end{tabular}

Chlordiazepoxide (CP): Saline (SA): Ro 15-1788 (RO); Ro 15-1788 + Chlordiazepoxide $(\mathrm{RO}+\mathrm{CP})$.

TABLE 2

ANALYSIS OF THE RESULTS OF PHASE II, WHERE CGS 8216 (CG) IS SUBSTITUTED FOR Ro $15-1788$

\begin{tabular}{lccccl}
\hline Taste & Reaction & $d f$ & $F$ & $p$ & Newman-Keuls $p<0.05$ \\
\hline \multirow{2}{*}{$0.03 \mathrm{M}$ Sucrose } & Ingestive & 3.18 & 8.83 & $<0.001$ & $\mathrm{CP}>\mathrm{SA} ; \mathrm{CG}+\mathrm{CP}>\mathrm{CP}$ \\
& Neutral & 3.18 & 4.64 & $<0.01$ & $\mathrm{CP}<\mathrm{CG}$; CG $>\mathrm{SA}$ \\
& Aversive & 3.18 & 2.70 & $>0.07$ & nil \\
$0.01 \mathrm{M} \mathrm{HCl}$ & Ingestive & 3.18 & 10.3 & $<0.001$ & $\mathrm{CP}>\mathrm{SA} ; \mathrm{CG}+\mathrm{CP}<\mathrm{CP}$ \\
& Neutral & 3.18 & 6.54 & $<0.003$ & $\mathrm{CP}<\mathrm{SA}$; CG+CP>CP \\
$3 \times 10^{-5} \mathrm{M} \mathrm{QHCl}$ & Aversive & 3.18 & 1.15 & $>0.35$ & nil \\
& Ingestive & 3.18 & 10.4 & $<0.001$ & $\mathrm{CP}>\mathrm{SA} ; \mathrm{CG}+\mathrm{CP}<\mathrm{CP}$ \\
& Neutral & 3.18 & 5.57 & $<0.007$ & $\mathrm{CP}<\mathrm{SA} ; \mathrm{CG}+\mathrm{CP}>\mathrm{CP}$ \\
& Aversive & 3,18 & 1.52 & $>0.24$ & nil \\
\hline
\end{tabular}

category for each animal were then analyzed with one-way repeated measures analyses of variance, with four levels representing each of the four drug conditions (chlordiazepoxide, saline, antagonist, and the combination of chlordiazepoxide and antagonist). When these analyses yielded significant $F$ values (Tables 1 and 2), the data were further analyzed with Newman-Keuls pair-wise comparisons $(p=0.05)$. An antagonism of CDP was indicated by (1) a significant difference between the combination of CDP + antagonist vs. CDP, and (2) no significant difference between the combination vs. saline. An intrinsic effect of the antagonist itself was indicated by a significant difference between it and saline.

\section{RESULTS}

Figure 1 shows the effects of the four drug conditions of Phase $I$ on the consummatory reactions elicited by each of the three tastes. The facilitative effect of CDP on ingestive reactions to sucrose, $\mathrm{HCl}$, and $\mathrm{QHCl}$, found in our previous study, was completely replicated in the present study, i.e., ingestive reactions to all three flavors were facilitated by
CDP compared to saline (see analyses in Table 1). Also consistent with our previous study was the selectivity of this facilitative effect of CDP. There was no facilitation by CDP of the neutral or aversive reactions elicited by the three tastes; in fact, there was a general tendency for neutral reactions to be reduced by CDP (Fig. 1). However, as we found previously, the suppressive effects of CDP on non-ingestive actions was less robust than the facilitation of CDP on ingestive actions, and was significant in the present study only in the case of neutral reactions elicited by $\mathrm{QHCl}$ (Table 1).

In general, Ro 15-1788 antagonized the taste-specific effects of CDP on rats' consummatory reactions (Fig. 1). Ro 15-1788 significantly antagonized the facilitative effect of CDP on the ingestive reactions elicited by sucrose, by quinine, but not by $\mathrm{HCl}$ (Fig. 1; Table 1). As expected on the basis of the lack of inverse agonist effects in previous consummatory-related paradigms [19], there was no hint in the present study that Ro 15-1788 exerted inverse agonist effects on ingestive reactions. On the contrary, the only significant intrinsic effect of Ro 15-1788 was actually parallel to its significant antagonism of the facilitative effect of CDP on ingestive reactions, i.e., when compared to saline, Ro 15- 


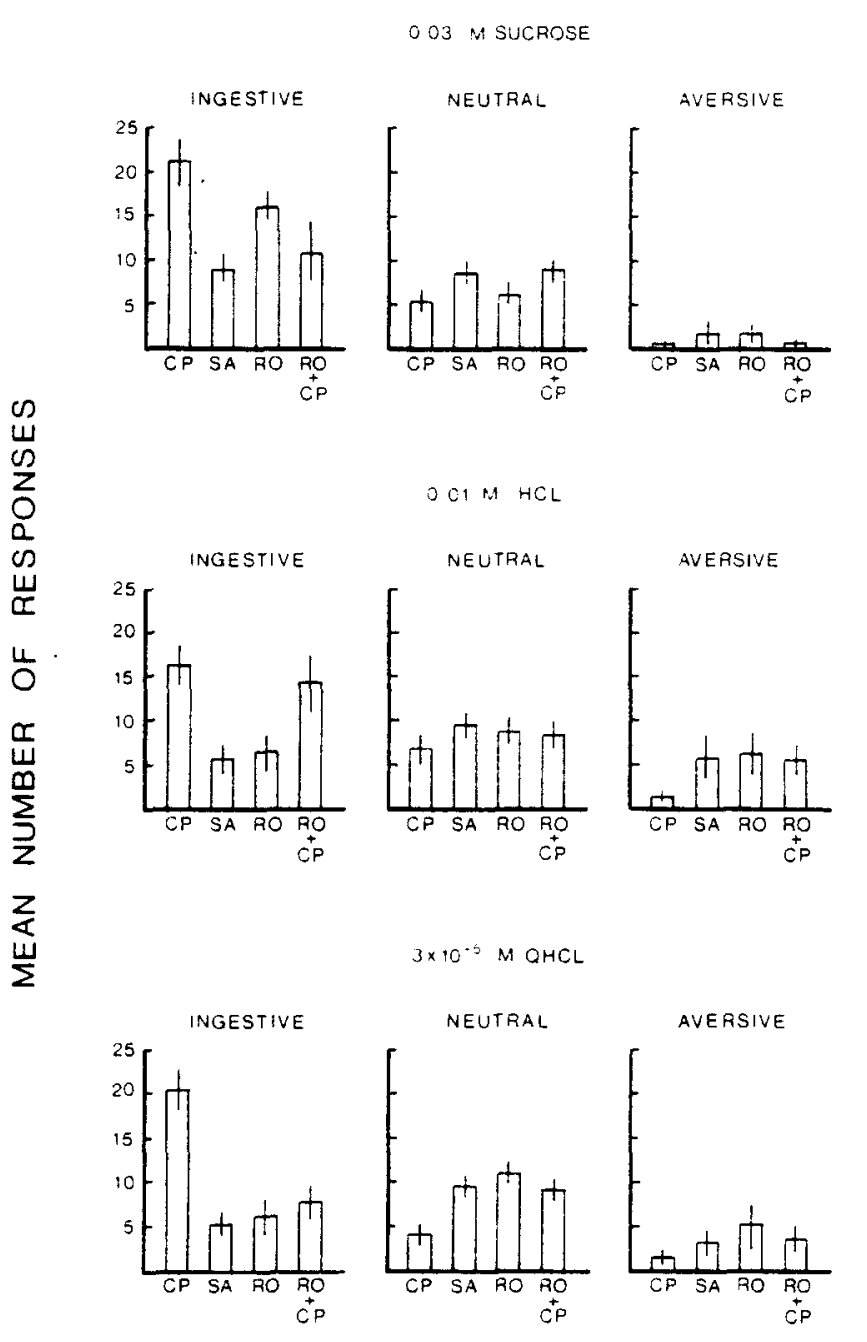

\section{DRUG CONDITION}

FIG. 1. The mean ( \pm SEM) of each of the three consummatory reactions. under each of the three taste conditions and each of the four drug conditions of Phase I. $C P=10 \mathrm{mg} / \mathrm{kg}$ chlordiazepoxide: $\mathrm{SA}=$ saline: $\mathrm{RO}=10 \mathrm{mg} / \mathrm{kg}$ Ro $15-1788: \mathrm{RO}+\mathrm{CP}=10 \mathrm{mg} / \mathrm{kg}$ Ro 15 $1788+10 \mathrm{mg} / \mathrm{kg}$ chlordiazepoxide.

1788 facilitated the ingestive reactions to sucrose. This agonist-like effect of Ro 15-1788 has been demonstrated in a previous taste study [38], perhaps suggesting that under restricted taste parameters (e.g.. $0.03 \mathrm{M}$ sucrose) Ro 15-1788 might be characterized as a mixed agonist/antagonist. Finally. Ro 15-1788 reversed the significant reduction in neutral reactions to $\mathrm{QHCl}$ produced by $\mathrm{CDP}$, without a significant intrinsic effect. There were no significant effects of any of the drug conditions on aversive reactions elicited by the three tastes (Table 1).

Figure 2 shows the effects of the four drug conditions of Phase II on the consummatory reactions elicited by the three tastes, where CGS 8216 was substituted for Ro 15-1788. The results with CGS 8216 generally parallel those of Ro 15-1788 displayed in Fig. 1. ANOVAs and subsequent NewmanKeuls comparisons (Table 2) showed that the facilitation by CDP of the ingestive reactions to each of the three flavors
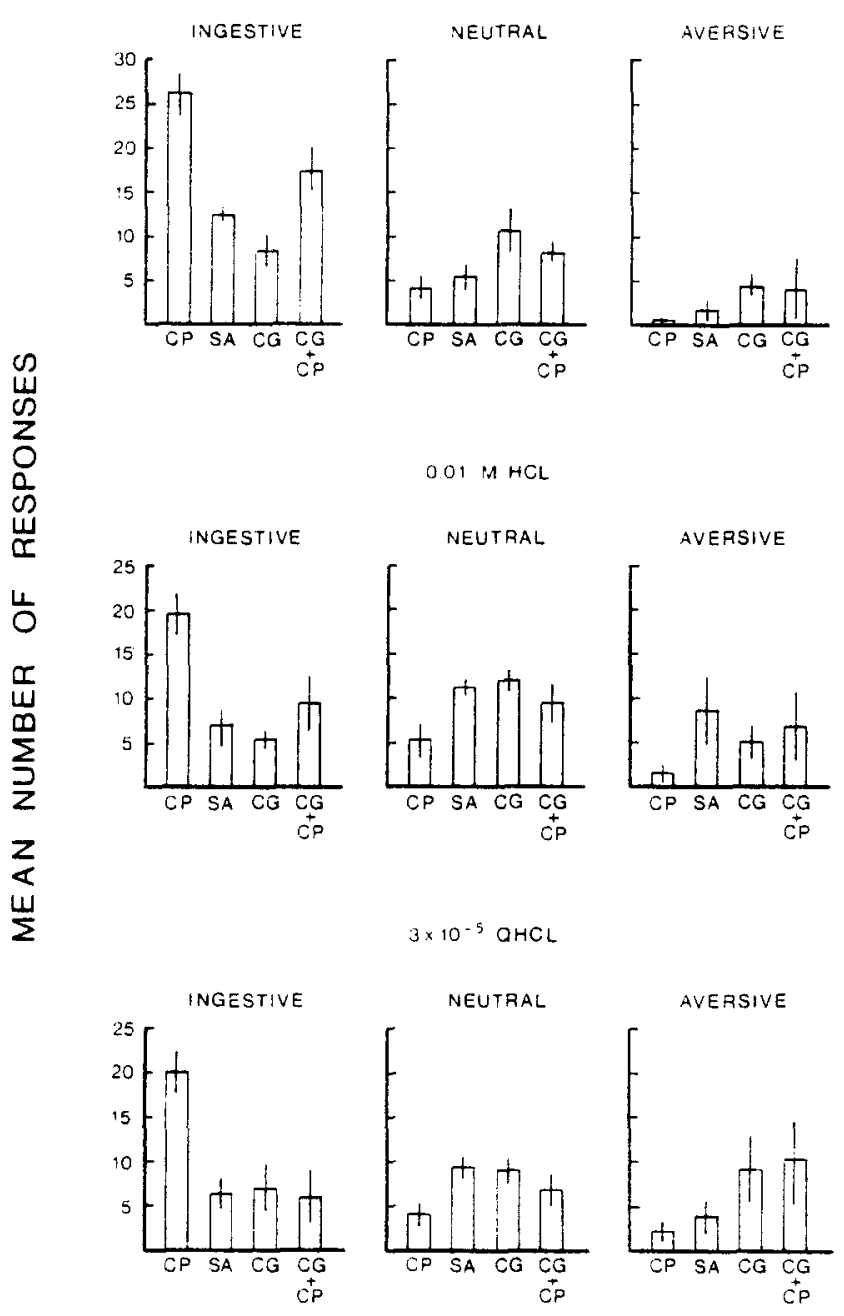

DRUG CONDITION

FIG. 2. The mean ( $=$ SEM) of each of the three consummatory reactions, under each of the three taste conditions and each of the four drug conditions of Phase II. CP $=10 \mathrm{mg} / \mathrm{kg}$ chlordiazepoxide; $S A=$ saline: $C G=10 \mathrm{mg} / \mathrm{kg}$ CGS $8216: C G+C P=10 \mathrm{mg} / \mathrm{kg}$ CGS 8216 $+10 \mathrm{mg} / \mathrm{kg}$ chlordiazepoxide.

was again replicated, with CDP in each case producing a significant facilitation compared to saline. CGS 8216 consistently antagonized these facilitative effects of CDP, and in no case did CGS 8216 have an intrinsic inhibitory effect by itself.

Also consistent with the results shown in Fig. 1 was the general suppression of neutral reactions produced by CDP (Fig. 2). CDP produced a significant reduction in neutral reactions to $\mathrm{HCl}$ and to $\mathrm{QHCl}$. but not to sucrose (Table 2). These inhibitory effects of CDP on neutral reactions were significantly antagonized by CGS 8216 , and CGS 8216 had no intrinsic effect on these reactions. In contrast. CGS 8216 produced a significant enhancement of the neutral reactions elicited by sucrose. Finally, consistent with the results in Phase I, none of the four drug conditions of Phase II produced a significant effect on the aversive reactions elicited by the three tastes (Table 2). 


\section{DISCUSSION}

There were several noteworthy findings in the present study. First, the direct facilitation of positive palatability reactions by $C D P$ was consistently replicated with every taste tested (cf. [8]). As we found in our previous study. the enhancement of taste-elicited ingestive actions was selective; neutral and aversive actions were not enhanced by CDP. Rather. non-ingestive actions were either not altered or else suppressed after CDP. This special sensitivity of ingestive actions to enhancement by CDP supports our earlier suggestion that benzodiazepines promote feeding in part by selectively amplifying the perceived positive palatability of foods, while having little or no effect on the negative or aversive aspects of palatability. This interpretation is consistent with the model of separate parallel processing of positive and negative palatability, presented by Berridge and Grill [7].

Second, this selective increase in positive palatability reactions produced by CDP was, in five out of six tests, uniformly counteracted by the benzodiazepine antagonists Ro 15-1788 and CGS 8216. suggesting that the "benzodiazepine receptor complex" might be involved in modulating the hedonic value of specific tastes. CGS 8216, also known for its inverse agonist effects on the intake of palatable fluid [31], failed to produce significant anorectic effects in the present paradigm, possibly because of a "floor effect." In fact. out of nine tests, each benzodiazepine antagonist produced only one intrinsic effect of any kind. Like CGS 8216, Ro 15-1788 did not appear to display inverse agonist effects in the taste infusion paradigm; instead, it produced an intrinsic facilitation of ingestive reactions to sucrose (cf. [38]). Further work is needed in order to understand these effects of Ro 15-1788 and CGS 8216 in the taste-infusion paradigm, and the relation of these to their effects in simple intake paradigms.

Another noteworthy finding was that these two benzodiazepine antagonists inhibited both the increases and the decreases in consummatory reactions produced by CDP. Thus, the results are difficult to explain in terms of an undetected. general effect of the antagonists (e.g., proconvulsant or anxiogenic), which might have indirectly mediated their antagonist actions on CDP. Instead, the effects found in the present study appear to reflect actions at the benzodiazepine receptor complex. Accordingly, the results of our experiments [8], and the recent work of Cooper and his associates (e.g., [19.31]) suggest the following hypothesis: The neural control of ingestive responses that is exerted by the benzodiazepine receptor complex is due in part to its modulation of the positive palatability of tastes (cf. [19]).

\section{ACKNOWLEDGEMENTS}

This study was supported by an NSERC grant (U0302) awarded to D. Treit and by grants from the Rackan Faculty of the University of Michigan and NIH (NS23959) awarded to K. C. Berridge.

\section{REFERENCES}

1. Anderson-Baker, W.. C. L. McLaughlin and C. A. Baile. Oral and hypothalamic injections of barbiturates, benzodiazepines and cannabinoids and food intake in rats. Pharmacol Biochem Behar 11: 487-491, 1979.

2. Ayd. F. J. A critical appraisal of chlordiazepoxide. $J$ Neuropsychiatry 3: 117-180, 1962.

3. Baile, C. A. and C. L. McLaughlin. A review of the behavioral and physiological responses to elfazepam, a chemical feed intake stimulant. J Anim Sci 49: 1371-1395, 1979.

4. Bainbridge, J. G. The effect of psychotropic drugs on food reinforced behavior and on food consumption. Psychopharmacologia 12: 204-213. 1968.

5. Bernard, P. S., G. Pastor and J. M. Liebman. CGS 8216, a benzodiazepine antagonist, reduces food intake in fooddeprived rats. Pharmacol Biochem Behav 24: 1703-1706, 1986.

6. Bertino, M., G. K. Beauchamp and K. Engelman. Taste perceptions in three individuals on a low sodium diet. Appetitc 2: 67-73, 1981 .

7. Berridge, K. C. and H. J. Grill. Isohedonic tastes support a two-dimensional hypothesis of palatability in rats. Appetite 5: 221-231, 1984.

8. Berridge, K. C. and D. Treit. Chlordiazepoxide directly enhances positive ingestive reactions in the rat. Pharmacol Biochem Behav 24: 217-221, 1986.

9. Berridge, K. C., H. J. Grill and R. Nogren. Relation of consummatory responses and preabsorptive insulin release to palatability and learned taste aversions. J Comp Physiol Psychol 95: 363-382, 1981.

10. Birk, J. and R. G. Noble. Bicuculline blocks diazepam-induced feeding in Syrian hamsters. Life Sci 30: 321-325. 1982.

11. Boast, C. A., P. S. Bernard, B. S. Barbaz and K. M. Bergen. The neuropharmacology of various benzodiazepine antagonists. Neuropharmacology 22: 1511-1521, 1983.

12. Britton. D. R. and K. T. Britton. A sensitive open field measure of anxiolytic drug activity. Pharmacol Biochem Behav 15: $577-582,1981$.
13. Brown, R. F., K. A. Houpt and H. F. Schryver. Stimulation of food intake in horses by diazepam and promazine. Pharmacol Biochem Behav 5: 495-497, 1976.

14. Cabanac, M. Physiological role of pleasure. Science 173: 1103-1107, 1971 .

15. Cole, S. O. Combined effects of chlordiazepoxide treatment and food deprivation on concurrent measures of feeding and activity. Pharmacol Biochem Behav' 18: 369-372, 1983.

16. Cooper, S. J. Hyperphagic and anorectic effects of $\beta$-carbolines in a palatable food consumption test: Comparisons with triazolam and quazepam. Eur J Pharmacol 120: 257-265, 1986.

17. Cooper, S. J. Effects of chlordiazepoxide on drinking compared in rats challenged with hypertonic saline, isoproterenol or polyethylene glycol. Life Sci 32: 2453-2459, 1983.

18. Cooper, S. J. Benzodiazepines as appetite-enhancing compounds. Appetite 1: 7-19, 1980.

19. Cooper, S. J. and L. B. Estall. Behavioral pharmacology of food, water and salt intake at benzodiazepine receptors. Neurosci Biobehav Rev 9: 5-19, 1985.

20. Cooper, S. J. and R. L. Francis. Water intake and time course of drinking after single or repeated chlordiazepoxide injections. Psychopharmacology (Berlin) 65: 191-195, 1979.

21. Cooper, S. J. and R. L. Francis. Effects of acute or chronic administration of chlordiazepoxide on feeding parameters using two food textures in the rat. $J$ Pharm Pharmacol 31: 743-746, 1979.

22. Cooper, S. J. and D. B. Gilbert. Clonazepam-induced hyperphagia in nondeprived rats: Tests of pharmacological specificity with Ro 5-4864, Ro 5-3663, Ro 15-1788 and CGS 9896. Pharmacol Biochem Behav 22: 753-760, 1985.

23. Cooper, S. J. and A. McClelland. Effects of chlordiazepoxide, food familiarization, and prior shock experience on food choice in rats. Pharmacol Biochem Behav 12: 23-28, 1980.

24. Cooper, S. J. and A. Posadas-Andrews. Food and water intake in the non-deprived pigeon after chlordiazepoxide administration. Psychopharmacology (Berlin) 65: 99-101, 1979. 
25. Cooper, S. J., D. J. Barber, D. B. Gilbert and W. R. Moores. Benzodiazepine receptor ligands and the consumption of a highly palatable diet in non-deprived male rats. Psichopharmacology (Berlin) 86: 348-355, 1985.

26. Della-Fera, M. A., C. A. Baile and C. L. McLaughlin. Feeding elicited by benzodiazepine-like chemicals in puppies and cats: Structure-activity relationships. Pharmacol Biochem Behav 12: 195-200, 1980.

27. Foltin, R. W. and C. R. Schuster. Interaction between the effects of intragastric meals and drugs on feeding in rhesus monkeys. J Pharmacol Exp Ther 266: 405-411, 1978.

28. Grill, H. J. and K. C. Gerridge. Taste reactivity as a measure of the neural control of palatability. In: Progress in Psychobiology and Physiological Psychology, edited by J. M. Sprague and A. N. Epstein. New York: Academic Press, in press.

29. Grill, H. J. and R. Norgren. The taste-reactivity test: I. Mimetic response to gustatory stimuli in neurologically normal rats. Brain Res 143: 263-279. 1978.

30. Haefely, W., L. Pieri, P. Polc and R. Schaffner. General pharmacology and neuropharmacology of benzodiazepine derivatives. In: Handbook of Experimental Pharmacology. Vol 55/II, edited by F. Hoffmeister and G. Stille. Berlin: Springer Verlag. 1981.

31. Kirkham, T. C. and S. J. Cooper. CGS 8216 , a novel anorectic agent, selectively reduces saccharin solution consumption in the rat. Pharmacol Bioche'm Behav 25: 341-345. 1986.

32. Mereu, G. P., W. Fratta, P. Chessa and G. L. Gessa. Voraciousness induced in cats by benzodiazepines. Psychopharmacology (Berlin) 47: 101-103, 1976.
33. Pelchat. M. L., H. L. Grill, P. Rozin and J. Jacobs. Quality of acquired responses to tastes by Rattus norvegicus depends on type of associated discomfort. $J$ Comp Psychol 97: 140-153. 1983.

34. Polc, P., E. P. Bonetti, R. Schaffner and W. Haefely. A threestate model of the benzodiazepine receptor explains the interactions between the benzodiazepine antagonist Ro 15-1788. benzodiazepine tranquilizers. $\beta$-carbolines, and phenobarbitone. Naunvn Schmiedehergs Arch Pharmacol 321: 260-264. 1982.

35. Randall, L. O.. W. Schallek. G. A. Heise, E. F. Keith and R. Bagdon. The psychosedative properties of methamino. diazepoxide. J Pharmacol Exp Ther 129: 163-171, 1960.

36. Shephard, R. A. and L. B. Estall. Anxiolytic actions of chloridazepoxide determine its effects on hyponeophagia in rats. Psychopharmacology (Berlin) 82: 343-347. 1984.

37. Stephens. R. J. The influence of mild stress on food consumption in untrained mice and the effects of drugs. $\mathrm{Br} J$ Pharmacol 47: $146 \mathrm{P}, 1973$.

38. Tang, M., S. Soroka and J. L. Falk. Agonistic action of a benzodiazepine antagonist: Effects of Ro 15-1788 and midazolam on hypertonic $\mathrm{NaCl}$ intake. Pharmacol Biochem Behav 18: 953955. 1983.

39. Tobin, J. M. and N. D. Lewis. New psychotherapeutic agent. chlordiazepoxide. Use in treatment of anxiety states and related syndromes. JA.MA 174: 1242-1249, 1960. 